\title{
Spontaneous haemorrhagic stroke complicating severe pre-eclampsia in pregnancy: a case report in a resource- limited setting in Cameroon
}

\author{
Paul Nkemtendong Tolefac ${ }^{1,2^{*}}$, Nkemnji Standley Awungafac ${ }^{1}$ and Jacqueline Ze Minkande
}

\begin{abstract}
Background: Spontaneous intracerebral haemorrhage is a rare complication of preeclampsia during pregnancy associated with a high morbidity and mortality. Compared with the non-pregnant women stroke rates are relatively rare during pregnancy.

Case presentation: We report the case of a 32-year-old female Cameroonian gravida 4 para 3 who presented at 34 weeks of gestation with sudden onset of right sided hemiplegia associated with headache, blurred vision and a blood pressure of 182/126. Cerebral CT scan confirmed a left parietal spontaneous haemorrhage. Emergency caesarean delivery was done and the recovery uneventful.

Conclusion: This case highlights the importance of good neurological examination in pregnant women presenting with neurological symptoms as well as the place of multidisciplinary management in severe life threatening conditions.
\end{abstract}

Keywords: Haemorrhagic stroke, Pre-eclampsia, Pregnancy, Severe preeclampsia, Case report

\section{Background}

Stroke is a clinical syndrome of rapidly developing clinical signs of focal (or global) disturbance of cerebral function, lasting more than $24 \mathrm{~h}$ or leading to death, with no apparent cause other than vascular origin [1], whereas intracerebral haemorrhage which is a type of stroke refers to rapidly developing clinical signs of neurological dysfunction attributable to a focal collection of blood within the brain parenchyma or ventricular system that is not caused by trauma [2]. Stroke being one of the major cause of disability has a higher impact on the society.

Stroke is an extremely rare event during pregnancy with the incidence ranging from 10 to 34/100,000 deliveries [3]. A recently conducted cohort in England showed that compared to non-pregnant women, stroke rates are lower during the antepartum period, 9-fold higher in the early peripartum period and 3-fold higher in the early postpartum period [4]. While the epidemiology of stroke in pregnancy in Africa and Cameroon remained largely unknown, the case fatality of stroke in Douala, Cameroon was estimated at $26.8 \%$ in a recent study by Mapoure et al [5].

The authors reports a case of a 32 year old female Cameroonian gravida 4 para 3 who presented at 34 weeks of gestation with sudden onset of right sided hemiplegia associated with headache, blurred vision and stage 2 hypertension. Cerebral (computed tomography) CT scan confirmed a left parietal spontaneous haemorrhage. Emergency caesarean delivery was done and the recovery uneventful. The aim of the case is to highlight the importance of rapid history and examination including neurological examination in pregnant women presenting with raised blood pressure. The authors adhered to the CARE guidelines/ methodology for reporting case reports [6].

\footnotetext{
* Correspondence: ptolefac15@gmail.com

${ }^{1}$ Faculty of Medicine and Biomedical Sciences, University of Yaoundé 1,

Yaoundé, Cameroon

${ }^{2}$ Mbalmayo District Hospita, Mbalmayo, Cameroon
}

\section{Case presentation}

A 32 year old female Cameroonian gravida 4 para 3 at 34 weeks of gestation presented to the labour and 
delivery unit of Mbalmayo district hospital with $8 \mathrm{~h}$ history of severe generalized headache, expressive aphasia and right sided paralysis in an afebrile context. This was associated with blurred vision but no convulsions. There was no epigastric pain and no difficulty breathing and no history of trauma or fall. For this current pregnancy, antenatal care (ANC) was started at 18 weeks with a booking blood pressure of 100/70 $\mathrm{mmHg}$. She did four ANCs and all were uneventful. During her routine four ANCs here blood pressure was always less than 140/90 $\mathrm{mmHg}$ and her urine dipsticks done during the four ANCs were all negative for proteinuria. She refused neurological symptoms such as headache during pregnancy. She has a history of gestational hypertension in her third pregnancy. There was no family history of chronic hypertension, diabetes and chronic kidney diseases. On examination she was afebrile with a blood pressure of $182 / 126 \mathrm{mmHg}$ and pulse of 112beats/minute. Neurological examination revealed Glasgow coma score of $13 / 15$, right sided hemiparesis and expressive Broca's aphasia, no signs of meningeal irritation. The abdomen was distended by a gravid uterus with a fundal height of $35 \mathrm{~cm}$, foetus in a longitudinal lie and cephalic presentation. The cervix was long, posterior, soft and closed with a station of -1 . We had a working diagnosis of severe pre-eclampsia complicated by stroke. Shown on Table 1 are laboratory investigations done and their results.

An emergency obstetric ultrasound showed a life foetus with an estimated foetal weight of $2300 \mathrm{~g}$ at 33 weeks of gestation. Emergency cerebral non contrast-CT scan showed a $3.2 \mathrm{~cm}$ hyperdense region in the left parietal lobe with surrounding hypodensity due to clot retraction as shown on Fig. 1. Emergency management by

Table 1 Results of initial laboratory investigations

\begin{tabular}{lll}
\hline Investigation & Result & Reference value \\
\hline Plasma glucose & $5.3 \mathrm{mmol} / \mathrm{L}$ & $3.9-6.1 \mathrm{mmol} / \mathrm{L}$ \\
Urea & $1.2 \mathrm{mmol} / \mathrm{L}$ & $2.0-7.1 \mathrm{mmol} / \mathrm{L}$ \\
Creatinine & $70 \mu \mathrm{mol} / \mathrm{L}$ & $50-110 \mu \mathrm{mol} / \mathrm{L}$ \\
Sodium & $132 \mathrm{mEq} / \mathrm{L}$ & $135-145 \mathrm{mEq} / \mathrm{L}$ \\
Potassium & $3.8 \mathrm{mEq} / \mathrm{L}$ & $3.5-5.5 \mathrm{mEq} / \mathrm{L}$ \\
Chloride & $109 \mathrm{mEq} / \mathrm{l}$ & $98-112 \mathrm{mEq} / \mathrm{L}$ \\
Alanine amino & $17 \mathrm{IU} / \mathrm{L}$ & $10-40 \mathrm{IU} / \mathrm{L}$ \\
transferase (ALAT) & & \\
Aspartate amino & $16 \mathrm{IU} / \mathrm{L}$ & $10-35 \mathrm{IU} / \mathrm{L}$ \\
transferase (ASAT) & & $36-92 \mathrm{IU} / \mathrm{L}$ \\
Alkaline phosphatase & $57 \mathrm{IU} / \mathrm{L}$ & $\mathrm{Negative}$ \\
$\begin{array}{l}\text { Urine dipstick } \\
\text { for protein }\end{array}$ & $3+$ & $12-16 \mathrm{~g} / \mathrm{dl}$ \\
Haemoglobin level & $11.8 \mathrm{~g} / \mathrm{dl}$ & $4.000-10.000 \mathrm{cells} / \mathrm{mm}^{3}$ \\
White cell count & $9.800 \mathrm{cells} / \mathrm{mm}^{3}$ & $150.000-400.000 \mathrm{cells} / \mathrm{mm}^{3}$ \\
Platelet count & $160.000 \mathrm{cells} / \mathrm{mm}^{3}$ &
\end{tabular}

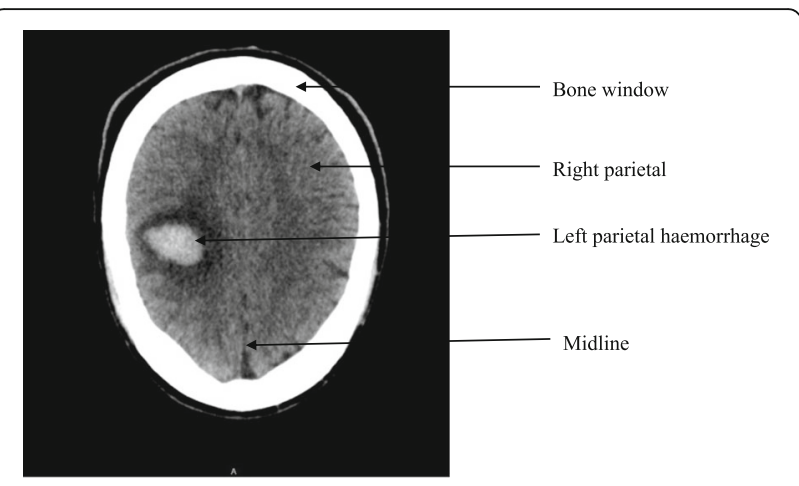

Fig. 1 Emergency cerebral CT scan showing spontaneous left parietal haemorrhage

the obstetrician consisted of MgSO4 using the Pritchard protocol [7], which consisted of $14 \mathrm{~g}$ loading dose then $5 \mathrm{~g}$ maintenance every $6 \mathrm{~h}$ until $24 \mathrm{~h}$ after caeserean section; bethamethasone $12 \mathrm{mg}$ intramuscular and reduction of blood pressure with nicardipine $5 \mathrm{mg} / \mathrm{h}$. Four hours later an emergency caesarean section was done by the obstetrician under spinal anaesthesia and it let to the extraction of a life female with APGAR 8 and 10 at the 1 st and 5th minute respectively and weight $2200 \mathrm{~g}$. The management after caesarean section consisted of hospitalization in the intensive care unit with nicardipine titrated in an electric syringe at $2.5 \mathrm{mg} /$ hour, ceftriaxone $2 \mathrm{~g}$ intravenous, Paractamol $1 \mathrm{~g} 8$ hourly, and ringers lactate 6 hourly for $24 \mathrm{~h}$. Post-operative management was done by a multidisciplinary team including a neurologist, cardiologist, intensive care physician, obstetrician, neonatologist and physiotherapist. On postoperative day 2 she was transferred from the intensive care unit to the maternity where she spends five additional days on nicardipine slow release $50 \mathrm{mg} 12$ hourly and paracetamol $1 \mathrm{~g}$ 8hourly and was later release after the ten days on nicardipine $50 \mathrm{mg}$ daily and daily physiotherapy. Six weeks during routine postpartum visit the blood pressure was normal and patient was no longer aphasic and shet has regained the muscle strength partially. The baby was hospitalised in the neonatal unit for 10 days and discharged alongside the mother.

\section{Discussion and conclusions}

Recent studies have demonstrated that stroke is a rare event during pregnancy with incidence relatively lower in the antepartum period compared to non-pregnant women [5]. In one study risk factors of stroke during pregnancy were found to include: sociodemographic factors such as age $\geq 35$ years $(R=2.2,95 \% \mathrm{CI}=1.2-2.2)$, African-American $(\mathrm{OR}=1.5,95 \% \mathrm{CI}=1.2-1.9)$; medical and obstetric determinants such as migraine headache $(\mathrm{OR}=16.9,95 \% \mathrm{CI}=9.7-29.5)$, thrombophilia $(\mathrm{OR}=$ 16.0, $95 \% \mathrm{CI}=9.4-27.2$ ), systemic lupus erythematosus 
$(\mathrm{OR}=15.2,95 \%=\mathrm{CI}$ 7.4-31.2), heart disease $(\mathrm{OR} 13.2$, $95 \%=\mathrm{CI} 10.2-17.0)$, sickle cell disease $(\mathrm{OR}=9.1,95 \%$ $\mathrm{CI}=3.7-22.2)$, hypertension $(\mathrm{OR}=6.1,95 \% \mathrm{CI} 4.5-8.1)$ and thrombocytopenia $(\mathrm{OR}=6.0,95 \%=\mathrm{CI}$ 1.5-24.1), postpartum haemorrhage (OR $1.895 \% \mathrm{CI}=1.2-2.8$ ) preeclampsia and gestational hypertension $(\mathrm{OR}=4.495 \%$ CI 3.6-5.4) [8]. Hypertension remain one of the main easily reversible risk factor and focus of treatment of stroke in pregnancy $[9,10]$. In the indexed case presented, the only risk factor identified was pre-eclampsia / hypertension. Her haemoglobin electrophoresis was AA and platelet count normal, however due to the limited capacity of the laboratory we could not assess for thrombophilia and systemic lupus erythematosus.

Compared with women without hypertension, women with a hypertensive disorder in pregnancy are six- to nine-fold more likely to develop stroke in pregnancy [8, 11].The role of pre-eclampsia in stroke has earlier been described in a review in 2013 which showed that pre-eclampsia / eclampsia is usually associated with about a third of stroke cases in pregnancy [12]. The most common type of stroke associated with pre-eclampsia / eclampsia is haemorrhagic stroke $[13,14]$.

The diagnosis is usually confirmed by a cerebral non-contrast computed tomography (CT) scan which will show a region of spontaneous hyper-density in the case of haemorrhagic stroke [15]. Contrary to public opinions, cerebral CT scan is not contraindicated in pregnancy because the radiation doses exposed to during a cerebral CT scan are well below the threshold of risk of foetal teratogenicity [16]. Cerebral (magnetic resonance imaging) MRI is the imaging modality of choice in case of suspicion of acute ischaemic stroke [16-18]. The regular unavailability and high cost of this imaging modality limited it use in favour for a cerebral CT scan which is readily available and affordable in our resource low-setting. In the indexed case cerebral CT scan showed spontaneous intracerebral haemorrhage in the parietal lobe. The management of stroke in pregnancy is multidisciplinary involving the obstetrician, neurologist, neurosurgeon, intensivist, anaesthetist, physiotherapist and paediatrician.

The main aim of management is to maintain cerebral perfusion pressure prevent secondary brain injuries [17] and deliver the baby and the placenta. Blood pressure should be reduced judiciously in the acute phase with a target of $\leq 160 / 110$ [19]. Intravenous labetalol has been widely used as first line for the reduction of blood pressure in patients with stroke during pregnancy [12]. MgSO4 should be added in the acute management for eclampsia prophylaxis [17]. Our indexed case described herein received intravenous nicardipine for control of blood pressure due to the unavailability of intravenous labetalol in our resource-limited setting and $\mathrm{MgSO} 4$ using the Pritchard protocol for prevention of seizures [7]. The timing and mode of delivery is influenced by fetal condition, gestational age and severity of associated preeclampsia [17]. Historically, caesarean delivery has been advocated and is increasingly being used to circumvent the potential risks during labour and delivery $[20,21]$. This was the mode of delivery in our patient which let to the extraction of a life female baby. The prognosis of haemorrhagic stroke occurring during pregnancy is more severe compared to ischaemic stroke [22].

\section{Conclusion}

Albeit the relative rarity of this condition in pregnancy, this case highlights the importance of a good neurological examination in a pregnant woman presenting with neurological symptoms and raised blood pressure. It also illustrate the importance of a well equip and multidisciplinary team in the management of emergencies. Finally it demonstrates the importance of early and aggressive management in life threatening conditions such as haemorrhagic stroke. The initiation of clinical registries are a potential avenue to increase awareness around these fatal conditions and thereby contribute to reduction of cardiovascular related morbidity and mortality. The author suggests a case control study should be carried out in order to well describe determinants of intracerebral haemorrhage in pregnancy.

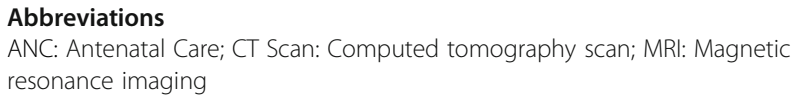

Acknowledgements

We express our sincere gratitude to all doctors, nurses and medical students who took part in the management of the patient.

Funding

None.

Availability of data and materials

The data analysed during this study are included in this published article.

Author's contributions

PNT conceived and wrote the draft manuscript, NSA \& JZM corrected the original manuscript and provided important intellectual information; all authors corrected and approved the final manuscript.

Ethics approval and consent to participate

Ethical approval was obtained from Mbalmayo district hospital. Written informed consent was obtained from the patient after treatment. A copy of is available for review by the Editor-in-Chief of this journal.

\section{Consent for publication}

Written informed consent was obtained from the patient for publication of this case report and any accompanying images. A copy of the written consent is available for review by the Editor-in-Chief of this journal.

\section{Competing interests}

"The authors declare that they have no competing interests" in this section. 


\section{Publisher's Note}

Springer Nature remains neutral with regard to jurisdictional claims in published maps and institutional affiliations.

Received: 6 July 2018 Accepted: 17 December 2018

Published online: 27 December 2018

\section{References}

1. Aho K, Harmsen P, Hatano S, Marquardsen J, Smirnov VE, Strasser T. Cerebrovascular disease in the community: results of a WHO collaborative study. Bull World Health Organ. 1980:58(1):113-30.

2. Sacco RL, Kasner SE, Broderick JP, Caplan LR, Connors JJ. (buddy), Culebras a, et al. an updated definition of stroke for the 21st century: a statement for healthcare professionals from the American Heart Association/American Stroke Association. Stroke. 2013 Jul 1:44(7):2064-89.

3. Jaigobin C, Silver FL. Stroke and pregnancy. Stroke. 2000 Dec;31(12):2948-51.

4. Ban L, Sprigg N, Sultan AA, Nelson-Piercy C, Bath PM, Ludvigsson JF, et al. Incidence of first stroke in pregnant and nonpregnant women of childbearing age: a population-based cohort study from England. J Am Heart Assoc. 2017 Apr 1:6(4):e004601.

5. Mapoure YN, Kuate C, Tchaleu CB, Ngahane HBM, Mounjouopou GN, Ba H, et al. Stroke epidemiology in Douala: three years prospective study in a teaching Hospital in Cameroon. World J Neurosci. 2014 Oct 23;04(05):406.

6. Gagnier JJ, Kienle G, Altman DG, Moher D, Sox H, Riley D, et al. The CARE guidelines: consensus-based clinical case reporting guideline development. BMJ Case Rep. 2013 Oct:23:2013.

7. Joshi S. Algorithm and Standard Management Protocol for Eclampsia. [cited 2017 Aug 17]; Available from: https://www.academia.edu/4497772/ Algorithm_and_Standard_Management_Protocol_for_Eclampsia

8. James $A H$, Bushnell CD, Jamison MG, Myers ER. Incidence and risk factors for stroke in pregnancy and the puerperium. Obstet Gynecol. 2005 Sep; 106(3):509-16.

9. Fairhall JM, Stoodley MA. Intracranial haemorrhage in pregnancy. Obstet Med. 2009 Dec 1;2(4):142-8.

10. Rezai S, Faye J, Hughes A, Cheung M-L, Cohen JR, Kaia JA, et al. Hemolysis, elevated liver enzymes, and low platelets, severe fetal growth restriction, postpartum subarachnoid hemorrhage, and craniotomy: a rare case report and systematic review. Case Rep Obstet Gynecol. 2017;2017:1-5.

11. Lanska DJ, Kryscio RJ. Risk factors for peripartum and postpartum stroke and intracranial venous thrombosis. Stroke. 2000 Jun;31(6):1274-82.

12. Crovetto F, Somigliana E, Peguero A, Figueras F. Stroke during pregnancy and pre-eclampsia. Curr Opin Obstet Gynecol. 2013 Dec;25(6):425-32.

13. Bateman BT, Schumacher HC, Bushnell CD, Pile-Spellman J, Simpson LL, Sacco RL, et al. Intracerebral hemorrhage in pregnancy frequency, risk factors, and outcome. Neurology. 2006 Aug 8;67(3):424-9.

14. Bushnell C, Chireau M. Preeclampsia and Stroke: Risks during and after Pregnancy. Stroke Res Treat [Internet]. 2011 Jan 20 [cited 2017 Aug 16]; 2011. Available from: http://www.ncbi.n/m.nih.gov/pmc/articles/ PMC3034989/

15. Sibai BM, Coppage KH. Diagnosis and management of women with stroke during pregnancy/postpartum. Clin Perinatol. 2004 Dec;31(4):853-68 viii.

16. Turan TN, Stern BJ. Stroke in pregnancy. Neurol Clin. 2004 Nov;22(4):821-40.

17. Kane SC, Dennis A, da Silva Costa F, Kornman L, Brennecke S. Contemporary Clinical Management of the Cerebral Complications of Preeclampsia [Internet]. Obstetrics and Gynecology International. 2013 [cited 2017 Aug 17]. Available from: https://www.hindawi.com/journals/ogi/2013/985606/

18. Zeeman GG. Neurologic complications of pre-eclampsia. Semin Perinatol. 2009;33(3):166-72.

19. Hart LA, Sibai BM. Seizures in pregnancy: epilepsy, eclampsia, and stroke. Semin Perinatol. 2013 Aug 1;37(4):207-24.

20. Cohen-Gadol AA, Friedman JA, Friedman JD, Tubbs RS, Munis JR, Meyer FB. Neurosurgical management of intracranial lesions in the pregnant patient: a 36-year institutional experience and review of the literature. J Neurosurg. 2009 Dec;111(6):1150-7.

21. Grear KE, Bushnell CD. Stroke and pregnancy: clinical presentation, evaluation, Treatment and Epidemiology. Clin Obstet Gynecol. 2013 Jun;56(2):350-9.

22. Laadioui M, Bouzoubaa W, Jayi S, Fdili FZ, Bouguern $\mathrm{H}$, Chaara $\mathrm{H}$, et al Spontaneous hemorrhagic strokes during pregnancy: case report and review of the literature. Pan Afr Med J [Internet]. 2014 Dec 11 [cited 2017 Aug 17];19. Available from: http://www.ncbi.nlm.nih.gov/pmc/articles/ PMC4427470/

Ready to submit your research? Choose BMC and benefit from:

- fast, convenient online submission

- thorough peer review by experienced researchers in your field

- rapid publication on acceptance

- support for research data, including large and complex data types

- gold Open Access which fosters wider collaboration and increased citations

- maximum visibility for your research: over $100 \mathrm{M}$ website views per year

At BMC, research is always in progress.

Learn more biomedcentral.com/submissions 